\title{
Sexualidade infantil, gênero e uma educação a contrapelo
}

Infant sexuality, gender and an oncoming education

\author{
Virginia Georg Schindhelm \\ Marcia Nico Evangelista \\ Universidade Federal Fluminense
}

\section{Resumo}

$\bigcirc$ artigo dialoga com o desafio de trabalhar os temas gênero e sexualidade na educação da infância como construções sociais polêmicas pela multiplicidade de visões, crenças, tabus, interditos e valores dos que convivem na escola. Assim, buscamos: (1) dialogar com Benjamin e estudiosos da infância, gênero e sexualidade; (2) participar do cotidiano de duas escolas fluminenses, onde os sujeitos das histórias narram suas experiências; (3) registrar e construir dados empíricos para a pesquisa de doutoramento. Os resultados (1) desvelaram ocultamentos e silenciamentos sobre as temáticas; (2) expuseram experiências inusitadas do(a)s educadore(a)s e decisões com incertezas, singularidades e conflito de valores; (3) evidenciaram falas marcadas por angústias e constrangimentos sobre 0 sexual; (4) revelaram (des)conhecimentos da equipe pedagógica sobre gênero e sexualidade infantil.

Palavras-chave: Educação da infância. Gênero e sexualidade. Teses de Benjamin.

\section{Abstract}

This article discourses about the challenge of working gender and sexuality themes in infant education as social constructions which are controversies by the multiplicity of sights, beliefs, taboos, interdictions and values of those who are inserted in school. Our aim is to (1) discourse with Benjamin and studious of infant, gender and sexuality; (2) participate on the routine of two schools in Rio de Janeiro State where the subjects of the stories narrate their experiences; (3) register and raise empiric data for a research of doctoral degree. The results (1) reveal educators' hiding and silencing about these themes; (2) show difficult experiences which take educators to face new situations causing unusual situations and decisions in an uncertain, peculiar and conflict values; 3) show speaking carried by anxiety and duress about the sexual matter; (4) reveal the educating team's (un)knowing experience about children's sexuality.

Keywords: Infant education. Gender and sexuality. Benjamin 's thesis. 


\section{Considerações iniciais}

Na escola da infância, ainda hoje é notória a existência de programas baseados em propostas acerca do que se compreende como necessário, importante e bom para as crianças, reiterando a ideia de submissão da cultura infantil à cultura do adulto.

No entanto, a educação infantil pretende despertar o prazer de explorar, experimentar e enriquecer as experiências e os saberes das crianças, favorecendo novas descobertas. Ideal seria se estivessem incluídas também as que tangem às subjetividades e às sexualidades.

Por outro lado, os modos de contato, os usos do corpo e seus discursos ainda são envoltos por visões, crenças, tabus, interditos, valores e preconceitos, oriundos de uma cultura herdeira do período vitoriano', que encerrou cuidadosamente a sexualidade, mudou-a para o ambiente privado e reduziu-a ao silêncio. Recebemos esse patrimônio histórico e sociocultural, oriundo de uma ideologia moral permeada pelo puritanismo, que ainda hoje se cala sobre as experiências relativas ao gênero e à sexualidade infantil.

A vida cotidiana (PAIS, 2003) na escola é permeada por situações incomuns, inabituais e desconcertantes, onde adultos e crianças, atores no cenário escolar, vivenciam ações e acontecimentos culturais que podem parecer insignificantes, mas são formadores das interações na especificidade do trabalho com a infância.

$\mathrm{O} / \mathrm{a}$ educador(a) infantil, no seu delicado papel de permutador(a) da realidade social, enfrenta, no dia a dia, pontos de cruzamento como certo/ errado, normal/anormal, natural/antinatural, verdadeiro/falso. Nesse cenário defronta-se com escolha de valores a serem reproduzidos com as crianças, que nem sempre estão muito claros e definidos pela escola, apesar de suas responsabilidades nas construções, mudanças ou estagnações de saberes e de comportamentos, ao participarem ativamente no processo dos cuidados e da educação dos pequenos.

As experiências do educar, do ensinar e do aprender, enquanto processos de cultura, são vividas por educadore(a)s e crianças, que narram suas vivências e imprimem suas marcas como sujeitos de suas histórias. De acordo com Benjamin, 
[...] a narrativa, que durante tanto tempo floresceu num meio de artesão - no campo, no mar e na cidade -, é ela própria, num certo sentido, uma forma artesanal de comunicação. Ela não está interessada em transmitir o "puro em si" da coisa narrada como uma informação ou um relatório. Ela mergulha a coisa na vida do narrador para em seguida retirá-la dele. Assim se imprime na narrativa a marca do narrador, como a mão do oleiro na argila do vaso. (BENJAMIN, 1994, p. 205).

A experiência num conceito benjaminiano (1994a) relaciona-se com uma dimensão política, histórica e cultural em que os encontros coletivos refletem a riqueza das trocas e a sabedoria de viver algo que transforma e deixa rastros.

Narrar, do latim narrare, significa relatar, contar uma história. (CUNHA, 1986). É uma forma artesanal de comunicação por meio da qual um sujeito lembra algo que aconteceu, coloca essa experiência numa sequência de acontecimentos construídos na sua vida individual e também social.

$\bigcirc$ diálogo aberto das narrativas privilegia um belo encontro entre educadore(a)s e crianças, surgindo as condições de elaboração dos discursos e de trocas desses sujeitos. Nesse compartilhar de saberes e de opiniões, são produzidos discursos, tornando o espaço de troca em um campo fecundo para a produção de conhecimentos. Deste modo, o encontro com a narrativa ou com o outro abre trilhas para rememorações de experiências e possibilidades de tecer tantas outras.

Esse movimento de busca pelas rememorações está envolvido por momentos de inércias, de recorrências que nos convidam a descobrir as resistências, as astúcias, os sonhos daqueles que fizeram parte, enquanto sujeitos das ações. Dessa forma, destacamos a importância de, numa relação pedagógica, construirmos vínculos e oportunidades para vivermos e agirmos com as crianças as mais variadas experiências na escola.

Nessa variedade, incluímos aquelas relacionadas ao gênero e sexualidade pela relevância desses temas na construção das subjetividades. Nas interações imediatas, adultos e crianças vivem e revivem suas histórias numa história coletiva, com mediações e com confrontos que não se esgotam e nem se explicam por diferenças pessoais, mas que emergem da riqueza e da diversidade de experiências passadas e rememoradas. 
Configuramos assim a arte de educar, de ensinar e de aprender como um verdadeiro passeio questionador pelo mundo, uma experiência enriquecedora para a criação de novas possibilidades escolares em espaços que instiguem as perguntas e façam proliferar uma multiplicidade de ideias. Por que não resgatarmos nossas experiências vividas em outros tempos e em outras escolas para pensarmos hoje um mundo e uma escola diferentes e uma educação na direção contrária à esperada, ou simplesmente, a contrapelo?

Diante desse desafio, trazemos os temas gênero e sexualidade para dialogar com algumas ideias de Walter Benjamin sobre o que existe e, comumente, não é visto ou se finge não ver na educação da infância.

Escolhemos Benjamin por ser um autor crítico, com indagações sobre o tempo em que viveu e sobre um futuro que sempre se anuncia. A escola, por exemplo, no que tange aos temas gênero e sexualidade, assume práticas e pedagogias construídas no passado, as transmite sem mudanças e, muitas vezes, sem sentido para as crianças no presente, de modo a prepará-las para um suposto futuro.

Não vemos projetos educacionais com novidades relativas a esses temas e, por isso, questionamos: como pensar a educação dentro de uma realidade denunciada por Benjamin de que o passado é uma obra inacabada sobre a qual, nós, educadore(a)s, devemos trabalhar?

\section{Uma pesquisa sobre gênero e sexualidade em escolas para infância}

Estudamos a sexualidade como uma construção social relacionada ao poder e à regulação (FOUCAULT, 1977) que, ainda hoje, é difícil de ser trabalhada na escola pelo desafio e pela grande transformação que promove na prática educativa, ao desvelar os ocultamentos e silenciamentos acerca da temática. Expressa crenças, atitudes, valores, papéis e relacionamentos, é produto de um trabalho permanente de ocultação, de dissimulação ou de mistificação, o que denota um reflexo do que se produz da mesma forma na sociedade.

Gênero é o conjunto de valores, atitudes, papéis, práticas ou características culturais que definem o que significa ser homem/mulher numa sociedade, por isso objeto de constante fluxo e de mudanças. (WEEKS, 2011 ). 
Os conceitos de gênero e sexualidade infantil são bem próximos, culturalmente construídos, carregados pela historicidade e pelo caráter provisório dos ambientes sociais que marcam os corpos dos adultos e das crianças, expressam-se nas suas vidas e práticas individuais e atingem igualmente as instituições, as normas e os arranjos das sociedades. (LOURO, 2008). Dessa forma, os distintos significados atribuídos às posições de gênero, masculino/ feminino e às expressões da sexualidade são atravessados por relações de poder e, usualmente, implicam hierarquias, subordinações e distinções.

gênero e a sexualidade são dimensões humanas com caráter dinâmico e mutável não apenas pelas particularidades culturais do meio onde são construídas, mas também pelo modo singular com que cada pessoa as assimila através de tradições sociais. Estão a serviço da vida e são transmitidas pelas gerações como uma bagagem cultural. E o que recebem as nossas crianças?

As crianças não são vazios históricos e culturais quando entram para a escola e por isso vivenciam as experiências no dia a dia com entendimentos não hegemônicos e de formas singulares. Num processo de interação com seus pares e com o(a)s educadore(a)s, dialogam e vivem experiências que atuam nos fazeres e saberes trazidos dos seus contextos familiares, inclusive os que constroem e reconstroem suas masculinidades/feminilidades.

Dessa forma, constroem-se numa relação processual, num movimento de produzir-se como sujeito, num corpo que se estende ao mundo e, ao mesmo tempo, é uma extensão de construções culturais. Assim, educador(a) e crianças aprendem e também ensinam rituais, regras, regulamentos, normas, atitudes, comportamentos, valores e orientações acerca da sexualidade e gênero, construídos, muitas vezes, de forma implícita, mas que se tornam aprendizagens sociais relevantes.

Nesse processo de ensino e aprendizagem torna-se fundamental que o(a)s educadorela)s estejam atentos para os corpos, sempre presentes por meio de gestos, posturas, tonalidades de voz, que passam a fazer parte do acervo que a criança coleciona ao longo de sua trajetória escolar. Segundo Benjamin, a criança é colecionadora na medida em que tudo que ela busca, perde, encontra, colhe, escolhe e captura já é para ela princípio de uma coleção e "[...] tudo que ela possui, em geral, constitui para ela uma coleção única." (BENJAMIN, 1993). 
As relações entre as crianças e os educadores são plenas de ditos e não ditos, de comunicação não verbal, possibilitando representações, que os pequenos vão aprendendo e resignificando num processo interativo. Nas sutilezas de atos, de gestos, de expressões faciais, constroem um campo semântico de enorme complexidade, no qual um sorriso pode variar de afirmativa de um fato à sua própria negação e a definição de sua conotação dependerá de um conjunto de fatores e significados relacionados ao contexto do sorrir.

Por meio dessa coleção de linguagens que a criança adquire na convivência com o(a)s educadore(a)s, este(a)s declaram o que pensam e sentem diante do outro e as crianças vão separando essas experiências de seus contextos e, assim, aprendendo e também ensinando tudo o que diz respeito aos temas gênero e sexualidade, num processo de ensino/aprendizagem sempre relacional e também sexuado, como afirma Fernández (1994).

Para muito(a)s educadore(a)s, a criança ainda é vista como um ser assexuado e, por isso, as práticas pedagógicas ainda tendem a investir nos saberes relacionados à mente sem falar sobre o corpo infantil, visto que este, como matriz da sexualidade, é uma realidade tão simbólica quanto física e palco de potenciais fontes de excitação sexual. Desde pequenos, o sentir 136 expressa prazeres e desprazeres e faz desabrochar emoções, afetos e desejos provocando sensibilidades num corpo que evidencia seu gênero e sua sexualidade.

Como construções sociais constituídas historicamente por discursos que as regulam, normatizam, instauram saberes e produzem verdades, os temas gênero e sexualidade são fortemente marcados pela cultura e pela história de cada sociedade, que impõe regras criadas e constituídas de parâmetros fundamentais de relevada influência no comportamento dos indivíduos.

$\bigcirc /$ a educador(a), pelas relações de poder e pela sua forma de saber, não apenas atua sobre as crianças por meio de seus gestos, condutas e linguagem, ensinando-as a agir de acordo com o que é considerado como normal para a escola, mas também ensina aos pequenos formas de dominar os seus prazeres e os seus desejos, num verdadeiro processo de controle de si.

A instituição escola, como um subgrupo social, comumente reproduz na educação das crianças, políticas de verdade sobre gênero e sexualidade, determinadas pelas correntes de pensamento, movimentos e tensões da 
comunidade a quem atende, de forma a enquadrar e normalizar as crianças dentro de padrões e de normas culturais.

Sabemos que não é fácil provocar mudanças porque elas deixam rastros e experiências que transmitem saberes e fazeres não prescritos, mas que transformam o modo de ensinar e de aprender por meio de conteúdos permeados de significados e sentidos passados, comunicados, narrados e aprendidos por gerações. (BENJAMIN, 1994). Essas experiências funcionam como se fossem elos que vinculam o sujeito ao passado e a tudo que a ele pertence enquanto patrimônio histórico e sociocultural. E o que faz parte do acervo que contempla esse acervo que herdamos sobre os temas gênero e sexualidade infantil?

sistema educativo introjeta valores e regras que servem para orientar comportamentos nas relações sociais. Enquanto os valores são genéricos e difundem-se pelo universo social, as regras são mais específicas, ligam-se aos comportamentos e constituem-se em guias para a ação, explicita Rodrigues (2006). As regras, associadas aos valores sociais, orientam condutas sociais dos indivíduos.

Sendo assim, numa sociedade como a nossa, com a tradição de que os assuntos referidos ao sexo e sexualidade ainda são da ordem do estritamente íntimo e privado, os códigos de conduta que recebemos e passamos para as nossas crianças apresentam esses temas como inadequados para 0 público infantil e, portanto, não deveriam ser falados ou sequer trabalhados com a infância. Percebemos, por isso, preconceitos e tabus, ainda que escondidos ou camuflados, mas que afloram nas falas, narrativas, comportamentos, aprovações e reprovações por parte dos adultos diante das experiências infantis no dia a dia da escola.

Como então educar e trabalhar com as crianças que ainda estão num processo de aquisição e de construção de valores e de regras de conduta, mas que expressam com tanta naturalidade e espontaneidade suas sensações e seus desejos, inclusive os sexuais? Que caminhos trilhar para educar as crianças?

Para discutir essas questões, trazemos dados construídos a partir da pesquisa de doutoramento realizada em duas escolas para a infância no estado fluminense, que buscou conhecer as concepções e as práticas de educadore(a)s sobre gênero e sexualidade infantil. 
A investigação de cunho qualitativo foi vivida de maneira participativa e atuante nos cenários escolares na medida em que associou nossa presença, dialogando e interagindo com o(a)s educadore(a)s e com as crianças nos cotidianos das instituições, com nossa participação e troca de conhecimentos no processo de formação continuada mensal desses profissionais de educação infantil. Registramos as nossas observações livres e as narrativas das crianças e da equipe pedagógica num diário de campo, que fluíram numa escrita pessoal e, posteriormente, foram dialogadas com olals educadorela)s.

Ao longo de todo o processo investigativo, efetuamos uma minuciosa análise bibliográfica priorizando teses de estudiosos da infância, do gênero e da sexualidade. Realizamos entrevistas semiestruturadas individuais com o(a) s educadore(a)s, de modo a conhecer um pouco mais sobre as suas experiências, as suas concepções e as suas práticas relativas aos temas gênero e sexualidade infantil

o sujeito de nossa investigação foi o/a educador(a) infantil. No cotidiano de ambas as escolas, procuramos nos aproximar para interagir com o(a)s educadore(a)s que lidam com as turmas de crianças com quatro e cinco anos, por entendermos que, por volta dessa faixa etária, as crianças apresentam maior curiosidade, tudo querem saber e perguntar e, assim começam a ter mais interesse nos assuntos relativos ao gênero e à sexualidade. Com isso, esse(a)s educadore(a)s defrontam-se mais frequentemente com as vivências sexuais das crianças.

A nossa presença teve uma aceitação grande da maioria dessela educador(a) que, no dia a dia, nos permitiam sentar nas rodinhas, jogar, desenhar, pintar, modelar, brincar de casinha, de detetive, dentre outras tantas atividades que as crianças nos convidavam a participar no tempo em que lá estávamos.

Durante dois anos numa escola infantil vinculada a uma universidade federal e um ano numa escola municipal para a infância, interagimos com o(a)s educadore(a)s e as crianças. Assim, tivemos inúmeras oportunidades de presenciar cenas cotidianas de experiências que os pequenos vivenciavam no espaço escolar e, nelas, pudemos observar e conhecer os modos e as práticas do(a)s docentes para lidar com essas situações. Algumas vezes, tínhamos oportunidade de dialogar com ele(a)s sobre essas práticas, mas, em tantas outras, essas vivências foram deixadas para ser pensadas e dialogadas nos 
espaços de formação continuada onde participamos ao longo dos anos de nossa pesquisa.

Assim, por ocasião de nossas entrevistas, já estávamos bem familiarizados com as equipes de educadore(a)s das duas instituições, tendo a maioria aceitado o nosso convite, disponibilizando, pois, um pouco de suas histórias e experiências como educadore(a)s infantis. Foram vinte e três entrevistas realizadas ao todo, sendo nove ${ }^{2}$ entrevistas com educadores homens.

As crianças que desfrutam desses espaços expressam de forma livre e espontânea como estão se construindo como seres sexuais, como meninos ou meninas e, por isso, tendem a ser alvo de cuidados e também de vigilância. Comumente, quando adotam atitudes ou comportamentos relativos ao sexual não condizentes com aqueles esperados, instituídos ou normatizados pelo espaço escolar geram tensões e levam os educadores a decisões num terreno de grande complexidade, incerteza, singularidade e de conflito de valores.

Os pequenos, quando imbuídos por uma vontade de saber, promovem situações inusitadas relativas ao gênero e à sexualidade e, muitas vezes, provocam nos educadores sentimentos de desconhecimento e de impotência no confronto com questionamentos e inesperadas vivências.

Nossa inserção nas creches, promoveu diálogos e reflexões sobre a importância da criança ser reconhecida como um ser sexuado que, na relação com os seus familiares, pares e também com os educadores, está sujeita às influências sociais e afetivas nas suas escolhas e na construção de sua identidade, sua sexualidade, seu gênero e seus comportamentos. Nesse processo interativo com o outro, a criança não apenas desenvolve sua singularidade, internaliza e expressa sua condição ideológica, histórica e social, mas também aprende, ensina e transforma suas ações no contexto escolar. Nesse fluido processo inter-relacional, já nos primeiros anos da vida escolar, constroem suas identidades e suas concepções sobre gênero e sexualidade, como mostra o exemplo vivenciado por uma educadora e a importância da sua presença numa simples brincadeira infantil.

Brincando de grávida ela queria saber o que ia fazer, pois estava nascendo. E agora? A outra menina falou: 'vomita, vomita' e uma terceira: 'não é vomitando'. Aí elas me perguntaram e eu disse: não é vomitando pode ser de parto normal ou cesariana. Aí ela perguntou: 'como é parto normal e cesariana?' e eu expliquei que parto normal é pela vagina e cesariana dá um cortezinho e tira o bebê e ela decidiu: 'mas já tá nascendo então vai pela vagina mesmo.' (EDUCADORA, 2012). 
A narração das histórias que são contadas pelas crianças em seus cotidianos, seja na escola ou em outros espaços, sobre suas vidas, suas brincadeiras, suas ideias e suas formas de interpretar o mundo vêm como movimento de ressignificação das experiências do passado. As narrativas, por serem constituídas socialmente, são expressões de memórias coletivas que trazem a riqueza das múltiplas interpretações que cada sujeito carrega. Essa infinita capacidade humana de refletir e de reinventar o mundo forma os ingredientes essenciais para os novos movimentos, as novas criações. A narrativa transcrita reflete essa ideia de memória pertencente à vida subjetiva entrelaçada ao grupo social. Assim sendo, a beleza da experiência trazida por cada narrador está na descoberta da teia coletiva.

- complexo processo de rememorar histórias vividas ao longo da pesquisa desenvolvida nas creches se configura em um momento singular deste trabalho, porque percebemos as concepções de mundo, as escolhas de vida que mobilizaram os educadorelals demonstrando os seus interesses, os seus conceitos e os seus sentimentos, e a expressão da intensa conexão destes com seus contextos sócio-históricos.

As crianças são participantes ativos de um ambiente que se pensa previamente ordenado e prescrito por adultos para prover esses novos sujeitos sociais daquilo que pensaram ser essenciais para atender às suas necessidades individuais, sociais, cognitivas e emocionais. E onde estão as práticas e os saberes que podem ajudar os pequenos na construção de suas identidades e subjetividades como seres sexuais?

Uma reflexão mais meticulosa permitiu o desvendamento de conteúdos singulares que se enraízam num social, onde a escola é apenas um recorte no qual, embora com toda repressão, vem à tona os anseios, preconceitos e tabus aos temas gênero e sexualidade. Não seria o caso de tentarmos um movimento ao contrário?

Se pensarmos a escola como uma faceta privilegiada da sociedade, gostaríamos de acreditar numa visão ainda mais ampliada de trajetórias de vida que intercambiam não somente as experiências escolares, mas também outras tantas esferas de manifestações e de comportamentos vivenciados na relação entre as pessoas inseridas nesse espaço. 


\section{Refletindo sobre experiências da infância pertinentes aos temas gênero e sexualidade}

Benjamin não partilhava da ideia romantizada que a modernidade construiu da infância e via a criança não pela ótica infantilizada, todavia como indivíduo social, inserida na história e pertencente a uma classe social.

Diante desse olhar, os pequenos constroem seu mundo de coisas, não imitam o mundo dos adultos e fazem história a partir dos detritos, ou seja, de restos e de resíduos de coisas originárias de qualquer atividade do mundo adulto, todavia construídos numa relação nova e original, "[...] um microcosmos no macrocosmos" ressalta o autor. (BENJAMIN, 1994b).

A criança cria sua própria cultura a partir do despertar de sua atenção e da atração irresistível pelos detritos de coisas que surgem do mundo dos adultos. Nesses detritos, elas reconhecem o rosto que o mundo das coisas assume só para elas e, com eles, reconstroem novas coisas e refazem novos brinquedos subvertendo o real produzindo uma cultura que enxerga o mundo sob a dimensão da fantasia, da imaginação, da criação. Nisso, reside a singularidade infantil (BENJAMIN, 1994) que mais aproxima a criança do artista, do colecionador e do mago do que de um pedagogo bem-intencionado. (BENJAMIN, 1984).

No entanto, as experiências infantis comumente são vistas como pouco importantes e não muito valorizadas. Esse adulto, que um dia também desejou e experimentou o que as crianças querem, hoje sorri com ares de superioridade e, de antemão, desvaloriza os anos que viveu, converte-os em época de doces devaneios pueris, em enlevação infantil que precede a longa sobriedade da vida séria e que, hoje, se tornaram os bem-intencionados e os esclarecidos, como afirma Benjamin (1 984).

Vivemos, atualmente, em uma sociedade capitalista que enaltece as perspectivas produtivas enquanto as atividades não produtivas, como, por exemplo, o brincar das crianças, passam despercebidas. Não participar das histórias e experiências infantis seria uma forma de negar a própria existência e infância, segundo Benjamin (1994).

Muitas vezes, os brinquedos documentam como o adulto se coloca com relação ao mundo da criança. Há alguns que dão margem para a criança desenvolver a sua fantasia e há outros, simplesmente impostos, como expressão 
de uma nostalgia sentimental e de falta de diálogo. A criança responde brincando seja fazendo uso do brinquedo para uma correção ou mudando-o função. Também escolhe os seus brinquedos por conta própria, não raramente entre os objetos que os adultos jogaram fora. Assim, elas "[...] fazem história a partir do lixo da história [...]" (BENJAMIN, 1984, p. 14) e se aproximam dos "inúteis", dos "inadaptados" e dos marginalizados, como declara Benjamin.

Buscar uma educação que cumpra com as expectativas sociais atuais é um desafio pedagógico, filosófico e político e Walter Benjamin teceu fios que compõem essas três vertentes. Como pensar a educação infantil nessa perspectiva?

Como mencionamos anteriormente, não é fácil trabalhar com os temas gênero e sexualidade na educação da infância devido à multiplicidade de caminhos desses campos de conhecimento.

As teses de Benjamin apontam que os desvios e as imperfeições podem servir como diretrizes privilegiadas e férteis para a produção de conhecimentos na medida em que guardam segredos sobre a infinidade de caminhos possíveis a serem seguidos. De acordo com suas palavras

Todo conhecimento [...] deve conter um mínimo de contrassenso, como os antigos padrões de tapete ou de frisos ornamentais, onde sempre se pode descobrir, nalgum ponto, um desvio insignificante de seu curso normal. Em outras palavras: o decisivo não é o prosseguimento de conhecimento, mas o salto que se dá em cada um deles. (BENJAMIN, 1993, p. 264).

Nessa alegoria do tapete tecido de modo artesanal, Benjamin aponta para o que existe de belo e profundo na unicidade do pensamento, cuja autenticidade o distingue de outros e, por isso, o liberta para imperfeições e o disponibiliza para o inusitado. Assim também na produção do conhecimento cada sujeito tece os próprios fios de um tecido singular de ações para alcançar um caminho ao mesmo tempo que, também pelas interações, vai se transformando ao longo desse deambular.

Com base nesse pressuposto benjaminiano, levamo-nos a questionar se o(a)s educadore(a)s estão com um olhar sensivel para conhecer os interesses das crianças, os conhecimentos que são apropriados por elas e quais são os elementos culturais dos grupos sociais em que estão imersas. 
Considerando que gênero e sexualidade são internalizadas de forma subjetiva, em conformidade com tradições de culturas familiar, comunitária, religiosa, dentre outras, como poderia o(a) educador(a) infantil ser capaz de romper com o que traz de suas experiências sobre esses temas e abrir-se à possibilidade de vivenciar novas possibilidades aventurando-se a um lugar não previsto, a um perpétuo devir, de modo a promover em si um desfazer e um refazer?

Comumente trabalham no dia-a-dia com projetos que foram prescritos nos currículos de educação infantil, todavia não contemplam as vivências relativas ao gênero e à sexualidade que as crianças trazem para a escola como o questionamento de Diogo para a educadora enquanto desenhava: "você não tem cueca, tem calcinha, por quê?" (SCHINDHELM, 2012).

A criança espera do adulto respostas claras e objetivas sobre os seus questionamentos e, muitas vezes, não as recebem pelo desconhecimento do(a) educador(a) sobre temas considerados tão delicados e inapropriados para a infância.

Benjamin, no entanto, esclarece que

[...] a criança exige do adulto uma representação clara e compreensível, mas não "infantil". Muito menos aquilo que o adulto concebe como tal. E já que a criança tem um sentido aguçado mesmo para uma seriedade distante e grave, contanto que esta venha sincera e diretamente do coração. (BENJAMIN, 1984, p. 50).

Sabemos que os projetos educacionais não contemplam as experiências sobre gênero e sexualidade e que estas comumente são negadas ou mesmo invisibilizadas por educadore(a)s que, muitas vezes, sentem-se desprovido(a)s e pouco informado(a)s de saberes e experiências que possam prepará-los para melhor conviver com as singulares vivências infantis no contexto escolar.

Presenciamos, nos cotidianos de nossos campos de pesquisa, situações que desvelaram algumas tramas das relações pedagógicas, onde crianças e educadorelals viveram os seus embates e entraram em conflito no entrelaçamento do conhecimento escolar e aquele que os pequenos traziam de seus peculiares mundos infantis. Destacamos, como exemplo, a narrativa de uma educadora que viveu no seu dia-a-dia um embate apresentado por seu 
grupo de crianças e pediu ajuda para a coordenadora de modo a resolver uma experiência percebida como um grande problema: suas crianças estão brincando de "fazer amor".

Deitadas em colchonetes e escondidas sob lençóis ou cobertores, as crianças deitavam, riam e deliciavam-se com a intrigante brincadeira. Após algum tempo, participando da vida cotidiana em sala de aula, o grupo de crianças permitiu a entrada da coordenadora, para conhecer e também atuar nesse mágico universo, de modo a pegar um colchonete e um cobertor, escolher um amigo, deitar com ele no colchão, cobrir o corpo e, finalmente, fazer cócegas um no outro. Eis o segredo e o rito do 'brincar de fazer amor' inventado pelas crianças. (CARREIRO, 2010, p. 32).

As crianças escondiam-se para brincar de "fazer amor" porque sabiam pelas censuras e olhares controladores que esta era uma atividade proibida. No entanto, quando percebiam o controle mais frouxo, disfarçavam para evitar a repreensão e também a repressão oficial, deliciavam-se novamente com este jogo, numa lógica de experienciar uma irregularidade que não pudesse ser percebida. Afinal, o proibido não é mais gostoso? Neste "fazer amor", as 144 crianças gostavam de se encontrar a sós, sentiam-se muito próximas e entregavam-se ao prazer não apenas de brincar, mas também de resistir ao padrão de comportamento normativo imposto pela escola.

A educadora dos "transgressores", por sua vez, preocupada com as repercussões que a brincadeira das crianças poderia ter, caso transcendesse o espaço escolar, previa um complicado problema a resolver com as mães das crianças, caso tal fato viesse a acontecer. Temia a reação das famílias e as prováveis acusações sobre o (não) cuidado da instituição ao permitir que as crianças participassem de uma brincadeira com tal denominação. Estaria a escola fomentando nas crianças a apropriação de conhecimentos e práticas relativas à sexualidade? Quais fontes estariam originando a necessidade de receberem esse conhecimento? Conversas informais com a educadora revelaram que: (a) a brincadeira das crianças the tirava o sono, (b) "educação sexual não é tema próprio para a infância" e (c) orientações sobre o tema numa tenra idade deveriam emergir da família.

Outra narrativa ressalta o constrangimento de uma educadora que não aceitava e não sabia como lidar com a brincadeira de um garoto. 
Hélio (5 anos) escolheu uma fantasia de fada azul, um vestido longo acetinado, para desfilar pelo pátio durante os preparativos para comemorar os aniversariantes daquele mês. Ao som do coro dos colegas: 'é mulherzinha', o menino sorria, corria e rodopiava expressando muita alegria e prazer ao responder: 'sou mesmo e tenho vagininha.' (HÉllO, 2011$)$.

A educadora mostrava-se bastante confusa e preocupada perguntando se deveria deixar Hélio ser motivo de zombaria dos outros ou se deveria impedir que ele passasse por tal constrangimento. "Hélio fica sempre feliz ao brincar assim", ressaltava ela.

Essa experiência retrata uma vivência singular da criança, todavia uma angústia para a educadora por considerála voltada para o tema gênero e construções de masculinidades/feminilidades na infância. Conversamos por um tempo sobre essa experiência e a educadora abrandou a sua angústia diante do ocorrido. Nas semanas posteriores, perguntávamos à educadora sobre as brincadeiras de Hélio e ela, com muita tranquilidade relatava: "agora entendo que ele só quer se exibir e chamar atenção e isso não quer dizer que ele tá se construindo, com a nossa ajuda, como uma mulherzinha." (EDUCADORA, 201 la).

"Não sei o que fazer, então finjo que não vejo" (EDUCADORA, 201 1), declarou uma outra educadora. A fala foi proferida como um desabafo para uma vivência que ocorria com frequência em seu grupo e que envolvia certa menina que, deitada no colchonete, na hora do descanso, tinha por hábito tocar seu próprio corpo, na região genital, de maneira prazerosa. Para ela, aquele movimento significava uma forma de brincar com o seu próprio corpo, enquanto para os adultos que a olhavam, esta cena era, no mínimo, desconcertante.

Percebemos, nos diálogos que estabelecemos pelo espaço escolar, que os adultos sentem enorme constrangimento diante da criança que se masturba. Esta, no entanto, sente prazer nessa experiência autoerótica de exploração dos seus genitais. (SCHINDHELM, 2010a).

É bastante comum vermos no cotidiano apenas o que a experiência ${ }^{3}$ que já vivemos nos permite compreender. Assim, em muitos momentos, vemos a criança e seus fazeres com um olhar daquilo que já conhecemos e quando estas não são suficientemente amplas para permitir a compreensão de fazeres 
de outra ordem, as invisibilizamos, assim como fez a educadora, autora das palavras que trouxemos para este diálogo.

Na educação da infância, a criança é o sujeito do processo educativo e, por isso, o(a) educador(a) deveria conhecê-las, saber quais são as suas áreas de maior interesse, quais são as suas preferências, os seus desejos, suas facilidades e dificuldades para aprender, para relacionar-se com o outro, enfim, saber como é a sua vida dentro e fora da escola. Para tal, é necessário que esse adulto tenha sensibilidade, conhecimento e disponibilidade para observar, perguntar, responder e tentar articular o que a criança já sabe com os novos saberes que as propostas pedagógicas sugerem. Isso implica uma organização pedagógica flexível, aberta ao novo e também ao imprevisível, promovendo assim os saltos dos conhecimentos como sugere Benjamin (1984).

○ conhecimento, por sua vez, é uma construção coletiva e um produto cultural. Sendo assim, cabe ao adulto mediar as relações das crianças com os elementos da cultura promovendo trocas e descobertas que articulem diferentes áreas do conhecimento, inclusive as que tangem aos temas gênero e sexualidade.

Para tanto, compreendendo a importância das trocas e descobertas para o processo do conhecimento, buscamos a narrativa como proposta para uma relação de confiança, entre pesquisador e pesquisado, em que se torna preponderante a escuta sensível à fala do outro e a compreensão dos gestos demonstrados ao longo dos discursos. Para isto, Benjamin (1994) distingue a narrativa dos demais processos de comunicação, justificando sua tese através da seguinte reflexão: $O$ narrador retira da experiência o que ele conta: sua própria experiência ou a relatada pelos outros. E incorpora as coisas narradas à experiência dos seus ouvintes.

A investigação, ao privilegiar a narração como um percurso de rememorações, nos une enquanto educadores ao invés de nos aprisionar dentro de nossas óticas individualistas. Ao contarmos nossas histórias e experiências, cada um é tocado ao seu nível sem deixar de estar envolvido pelo tecido coletivo. Esse foi o brilho especial das narrativas que aqui destacamos: o enriquecimento dos saberes que são construídos com o outro.

O(a) educador(a) infantil não pode negar que ele representa uma autoridade para as crianças, na medida em que lhes transmite saberes adquiridos e invocados pela sua própria experiência (BENJAMIN, 1994a), aquela que 
modifica, forma e tem efeitos sobre a subjetividade do outro, (trans)formando-a ou (de)formando-a, como aponta Larossa (1995).

Diante disso, essa autoridade introduz as crianças, como novos membros da comunidade escolar, num universo de signos e também de significações e, por meio dessa educação, os pequenos entram em contato com uma cadeia de tradições, reminiscências nas palavras de Benjamin (1994), representados por acontecimentos e significados transmitidos de geração a geração. Pela tradição, o sujeito adquire o sentido de pertencimento a uma comunidade, um sentido de si mesma, do que ela é como herdeira de um passado e como responsável por um futuro como membro de uma coletividade. (LAROSSA, 1995).

É inegável que, apesar dos diferentes modos como as pessoas percebem suas experiências e os significados que a elas atribuem, ainda hoje vivemos permeados pela tradição oriunda de uma moral judaico-cristã que envolveu os temas sexo, sexualidade e gênero em tabus, mitos e repressões encerrando esses temas em práticas interditadas na infância, por isso, não verbalizadas, não discutidas e também não ensinadas.

Entretanto, as crianças ainda são bem espontâneas em suas brincadeiras e questionamentos e costumam agir com uma naturalidade que, quase sempre, surpreende o(a) educador(a), como neste rápido episódio cotidiano:

A turma foi dividida e uma parte dela foi levada ao atelier de arte. A educadora, separando o material para as crianças utilizarem na pintura, distribuía papéis, tintas e pincéis pelas mesas perguntando o quê cada um gostaria de pintar. Virou-se para a pia a fim de encher potinhos com água e ouviu risadas das crianças sem entender o motivo para tal. Ao virar-se para as crianças deparou-se com Dênis em cima da mesa com as calças abaixadas mostrando seu pênis para os colegas atentos a esta cena. A educadora perguntou se ele queria ir ao banheiro e pediu que ele guardasse o que exibia para a turma e a brincadeira terminou com o garoto obedecendo à educadora. (SCHINDHELM, 2010a).

Na escola, as crianças são participantes ativos de um ambiente previamente ordenado e prescrito por adultos para prover esses novos sujeitos sociais daquilo que pensaram ser essenciais para atender às suas necessidades individuais, sociais, cognitivas e emocionais. E onde estão as práticas e os saberes que podem ajudar os pequenos na construção de suas identidades e subjetividades como seres sexuais? 
Ao enxergar a realidade sob um prisma crítico, entendemos que as concepções de educação e de infância que perpassam nas escolas ou nas políticas de educação precisariam ser escovadas a contrapelo. Pensar a educação pelas lentes benjaminianas requer sacudir o cotidiano de nossas escolas, os projetos pedagógicos, as relações estabelecidas no contexto escolar, as políticas públicas que caem de paraquedas nas instituições sem, ao menos, considerar a história ou a memória das mesmas. Quando estudamos as contribuições sobre o pensar a educação a contrapelo significa recuperar o sentido de educar, de ensinar e de nos tornarmos narradores de nossas experiências, aluno(a)s e professore(a)s.

No entanto, os pequenos criam, todo dia, novas formas de ser, de fazer e de brincar, que, muitas vezes, subvertem a ordem estabelecida quando atravessam e extrapolam os contextos pedagógicos pensados e elaborados para a educação da infância. Por essa razão, trabalhar com os temas gênero e sexualidade na infância tem sido um desafio transformador da prática educativa, por isso tão delicado e conflituoso.

\section{Articulações (in)conclusivas}

Não é simples tratar dos temas sexualidade e gênero na educação infantil e menos ainda trabalhá-los no cotidiano com os pequenos, por serem costumeiramente desconsiderados pela equipe escolar ou mesmo não tratados na perspectiva de uma proposta pedagógica.

No entanto, mais importante do que os conteúdos ou as prescrições do que se pretende ensinar para meninos e meninas, é o modo como são vividos no cotidiano, seja pelas permissões, pelas negações ou pelas proibições. Seja qual for a maneira escolhida pela escola para lidar com as questões de gênero e sexualidade da infância, as crianças recebem uma educação sexual por meio de pedagogias sutis e discretas, nem sempre explícitas ou intencionais, mas eficientes e duradouras, esclarece Louro (2001).

A negação ou a omissão da sexualidade infantil é uma opção política, ainda que não seja explícita, verbalizada. Entretanto, apresenta-se materializada em diversas práticas evidenciadas no cotidiano escolar por breves observações. 
É possível que sejam, exatamente, esses pontos negados aqueles que adquirem maior significado nas trajetórias de vida das crianças, depois que se apagam as aprendizagens de conteúdos específicos, que recebem tanto apego por parte da maioria do(a)s educadore(a)s.

Uma reflexão mais meticulosa permitiu o desvendamento de conteúdos singulares que se enraízam num social em que a escola é, apenas, um recorte no qual, embora com toda repressão, vêm à tona os anseios, preconceitos e tabus aos temas gênero e sexualidade. Consideramos importante destacar: a) a ocultação de aspectos relativos à sexualidade das crianças nas práticas cotidianas, mostrando-nos que não são tão ocultos quanto possam parecer; b) reações, muitas vezes, ambivalentes dos educadores, que vivem seus embates e entram em conflito sobre a maneira de trabalhar e entrelaçar o conhecimento escolar e os seus conhecimentos de mundo, na medida em que, muitas vezes, não receberam, na formação profissional, saberes que possam prepará-los para conviver com o gênero e a sexualidade infantil no contexto escolar.

Incertezas, ambivalências, restrições dos educadores contribuem de forma negativa para o desenvolvimento sexual das crianças e podem oportunizar sentimentos de ansiedade, vergonha e culpa da criança em relação à construção de seu gênero e de sua sexualidade.

Quando entram para a escola, as crianças não são vazios culturais e trazem como bagagem um acervo de experiências que rompem e desmontam com o que foi prescrito nos projetos pedagógicos para a educação infantil.

Esses acontecimentos não fazem parte dos preceitos documentados pelas políticas públicas para a educação da infância e, por isso, promovem tensões (VEIGA-NETO, 2008) instauradas pela solidez e, muitas vezes, rigidez dos critérios estabelecidos pela escola em face da liquidez evanescente e a flexibilidade que as manifestações infantis relativas ao gênero e à sexualidade demandam.

Na escola, as experiências relativas ao gênero e à sexualidade emergem e escapam aos controles sociais exercidos pelos profissionais da educação. Essa instituição social revela, então, o seu lado de emancipador, na medida em que, num primeiro momento, é repressora, mas num outro, é geradora de um conjunto de práticas e manifestações sociais, políticas e culturais, que persistem e rompem com os cercos, por mais severos que sejam. 
A importância da temática gênero e sexualidade merece ser destacada por: a) ser refletida pelos educadores de modo a desmistificar os (des) conhecimentos e os (pre)conceitos sexuais experienciados na prática docente; b) buscar novas concepções que envolvam os aspectos vivenciados sobre gênero e sexualidade, no exercício da profissão, como alternativas e estratégias que sirvam de subsídios, capazes de contribuir para a melhoria do processo formativo docente, no sentido da construção de novas formas de discursos e práticas educativas.

Assim, as instituições escolares vêm caminhando com as contradições e as reinvenções de propostas educacionais. As tensões e os conflitos que são vividos no espaço escolar estão presentes, muitas vezes, nas políticas de educação que são gestadas por pessoas que não fazem parte daquele universo e, portanto, não identificam suas necessidades e seus sonhos. A experiência da educação mergulhada na atmosfera da descoberta nos provoca a tentar novas trilhas, a ousar novas propostas e a fugir do que nos causa tédio: a repetição automática e a falta de estranhamento. Acreditamos que, como educadore(a) $s$, poderemos recuperar a nossa vitalidade de reinventar o cotidiano e construirmos uma educação a contrapelo, um movimento ao contrário.

Os efeitos dessa amplitude podem promover a possibilidade de novas formas de atuar no cotidiano escolar. Além disso, dialogar e discutir sobre o problema é também uma possibilidade de despertar nos educadores interesse em buscar alternativas para reconstruir suas práticas pedagógicas.

Não seria esta uma forma de manter o sentido original da educação: o que deriva do ex-ducere de sua etimologia latina: conduzir para fora, para fora do que se é, para fora do caminho traçado de antemão, como nos ensina Larossa (1995)?

A certeza de que nossa atuação durante a pesquisa, junto à equipe escolar, adquiriu dimensões para além do que ficou escrito e declarado já foi um primeiro passo. Exercitamos as formas de perceber pequenos fatos, que nos escapavam, para dimensioná-los em outros patamares de discussão menos preconceituosos, como forma de encontrar outras alternativas interessantes e ricas no fazer escolar. 


\section{Notas}

1 período vitoriano remete a uma fase da história inglesa - a era vitoriana (1838-1901) quando a Inglaterra, sob o reinado da Rainha Vitória, passou por uma época muito conservadora para a vida cotidiana dos cidadãos, onde o sexo era um assunto proibido.

2 Na ocasião da pesquisa eram oito educadores homens trabalhando na escola municipal. A nona entrevista foi realizada com o primeiro educador a trabalhar nessa instituição que, apesar de não mais fazer parte da equipe docente, aceitou o convite para entrevistá-lo.

3 Em sua etimologia latina ex-per-ientia implica uma viagem, numa aventura, num sair para fora e num passar através de Larossa (1995).

4 O período vitoriano remete a uma fase da história inglesa - a era vitoriana (1838-1901) - quando que a Inglaterra, sob o reinado da Rainha Vitória, passou por uma época muito conservadora para a vida cotidiana dos cidadãos, onde o sexo era um assunto proibido.

5 Na ocasião da pesquisa eram oito educadores homens trabalhando na escola municipal. A nona entrevista foi realizada com o primeiro educador a trabalhar nesta instituição que, apesar de não mais fazer parte da equipe docente, aceitou o convite para entrevistá-lo.

6 Em sua etimologia latina ex-per-ientia implica numa viagem, numa aventura, num sair para fora e num passar através de Larossa (1995).

\section{Referências}

BENJAMIN, Walter. Reflexões: a criança, o brinquedo, a educação. Tradução Marcus Vinicius Mazzari. São Paulo: Summus, 1984.

BENJAMIN, Walter. Obras escolhidas. Rua de mão única. Tradução Rubens Rodrigues Torres Filho e José Carlos Martins Barbosa. São Paulo: Brasiliense, 1993. (obras escolhidas, v. 2)

BENJAMIN, Walter. $\bigcirc$ narrador. Considerações sobre a obra de Nikolai Leskov. In:

Obras escolhidas. Magia e técnica, arte e política. 7. ed. Tradução Sergio Paulo Rouanet. São Paulo: Brasiliense, 1994. (Ensaios sobre Literatura e História da Cultura: obras escolhidas, v. 1).

BENJAMIN, Walter. Experiência e pobreza. In:

Obras escolhidas. Magia e técnica, arte e política. 7. ed. Tradução Sergio Paulo Rouanet. São Paulo: Brasiliense, 1994a. (Ensaios sobre Literatura e História da Cultura: obras escolhidas, v. 1).

BENJAMIN, Walter. Livros infantis antigos e esquecidos. In: Obras escolhidas. Magia e técnica, arte e política. 7. ed. Tradução Sergio Paulo Rouanet. São Paulo: Brasiliense, 1994b. (Ensaios sobre Literatura e História da Cultura: obras escolhidas, v. 1). 
CARREIRO, Heloisa Josiele Santos. Brincadeiras de crianças e reflexões sobre a sexualidade no cotidiano da educação infantil. In: ENCONTRO NACIONAL DE DIDÁTICA E PRÁTICA DE ENSINO - ENDIPE, 15., 2010, Belo Horizonte. Anais... Belo Horizonte: UFMG, 2010, p. 27-38.

CUNHA, Antônio Geraldo da. Dicionário etimológico da língua portuguesa. 2. ed. Rio de Janeiro: Nova Fronteira, 1986.

EDUCADORA. Relato. Niterói, 03 maio. 2011

EDUCADORA. Relato. Niterói, 29 nov. 2011 a

EDUCADORA. Relato. Niterói, 10 abr. 2012.

FERNÁNDEZ, Alicia. A mulher escondida na professora: uma leitura psicopedagógica do ser mulher, da corporalidade e da aprendizagem. Tradução Neusa Kern Hickel. Porto Alegre: Artmed, 1994.

FOUCAULT, Michel. História da sexualidade. A vontade de saber. Tradução de Maria Theresa da Costa Albuquerque; José Augusto Guilhon de Albuquerque. Rio de Janeiro: Graal, 1977. (v. 1).

152 HÉllO. Relato. Niterói, 26 maio 2011.

LARROSA, Jorge. Pedagogia, experiência e subjetividade. Uma exploração da experiência do livro e da formação do leitor na educação humanística. In: SILVA, Luiz Heron; AZEVEDO, José Clóvis de (Org.). Reestruturação curricular: teoria e prática no cotidiano da escola. Petrópolis, RJ: Vozes, 1995.

LOURO, Guacira Lopes. Pedagogias da sexualidade. In: pedagogias da sexualidade. Belo Horizonte: Autêntica, 2001.

(Org.). O corpo educado:

Gênero, sexualidade e educação. Uma perspectiva pós-estruturalista. 10. ed.

Petrópolis: Vozes, 2008.

PAIS, José Machado. Vida cotidiana: enigmas e revelações. São Paulo, Cortez, 2003.

RODRIGUES, José Carlos. Tabu do corpo. 7. ed. rev. Rio de Janeiro: Fiocruz, 2006.

SCHINDHELM, Virginia. Diário de campo. Niterói, 15 mar. 2010.

SCHINDHELM, Virginia. Diário de campo. Niterói, 14 jul. 201 Oa.

SCHINDHELM, Virginia. Diário de campo. Rio de Janeiro, 27 mar. 2012. 
VEIGA-NETO, Alfredo. Currículo e cotidiano escolar: novos desafios. In: CONGRESSO INTERNACIONAL COTIDIANO: DIÁLOGOS SOBRE DIÁlOGOS, 2., 2008, Rio de Janeiro. Anais... Rio de Janeiro, Universidade Federal Fluminense, 2008, p.1-1 1.

WEEKS, Jeffrey. The languages of sexuality. London: Routledge, 2011.

Profa. Dra. Virginia Georg Schindhelm Universidade Federal Fluminense | Niterói Faculdade de Educação Núcleo de Estudos e Pesquisas da Educação Superior | NEPES Grupo de Estudos e Pesquisas com Crianças e Infâncias | GEPECl Email | psicovir@terra.com.br

Profa. Doutoranda Marcia Nico Evangelista Universidade Federal Fluminense Programa de Pós-Graduação em Educação Supervisora Pedagógica da Fundação Municipal de Educação de Niterói Coordenação de Supervisão Escolar das escolas de educação infantil de Niterói Núcleo de Estudos e Pesquisas da Educação Superior | NEPES E-mail | marcianico@gmail.com

Recebido 29 maio 2013 Aceito 17 jun. 2013 